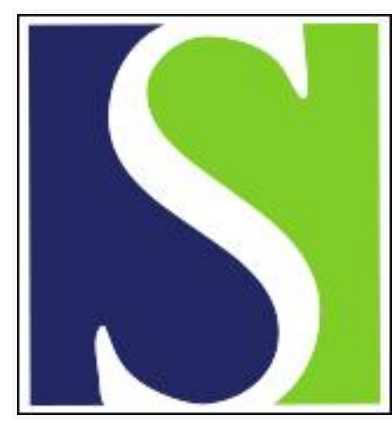

Scand J Work Environ Health 1996;22(4):251-259

https://doi.org/10.5271/sjweh.139

Issue date: Aug 1996

Validity of self-reported physical work load in epidemiologic studies on musculoskeletal disorders

by Viikari-Juntura E, Rauas S, Martikainen R, Kuosma E, Riihimäki H, Takala E-P, Saarenmaa K

The following articles refer to this text: 2001;27(1):30-40;

2002;28(5):293-303; 2004;30(4):279-286; 2008;34(6):411-419;

2009;35(1):48-55; 2009;35(4):245-260; 2013;39(1):37-45;

2023;49(1):53-63; 0;0 Special issue:0

Key terms: diary; ergonomics; logbook; low-back pain; neck pain; physical exposure; questionnaire study; work analysis

This article in PubMed: www.ncbi.nlm.nih.gov/pubmed/8881013 


\title{
Validity of self-reported physical work load in epidemiologic studies on musculoskeletal disorders
}

\author{
by Eira Viikari-Juntura, DMedSc, ${ }^{1}$ Sirpa Rauas, ${ }^{1}$ Rami Martikainen, MSc, ${ }^{1}$ Eeva Kuosma, MSc, ${ }^{1}$ \\ Hilkka Riihimäki, DMedSc, ${ }^{1}$ Esa-Pekka Takala, DMedSc, ${ }^{1}$ Kari Saarenmaa, MSc ${ }^{1}$
}

\begin{abstract}
Viikari-Juntura E, Rauas S, Martikainen R, Kuosma E, Riihimäki H, Takala E-P, Saarenmaa K. Validity of selfreported physical work load in epidemiologic studies on musculoskeletal disorders. Scand J Work Environ Health $1996 ; 22: 251-9$.

Objectives This study assessed the validity of self-reported physical work load by questionnaire and logbook against task analysis and observation. It also investigated factors (job type and low-back or neck pain) affecting the self-assessment of physical work load and compared the assessments between the questionnaire and the logbook.

Methods A self-administered questionnaire including 10 questions (ordinal scales) on physical work load and musculoskeletal symptoms was filled out by 2756 men in the forest industry. From this population, 36 men were selected for task analysis and observation. Logbooks including 10 continuous variables were analyzed for 386 men.

Results The Spearman rank correlation coefficients between the self-assessments and observations for the frequency of manual handling, duration of trunk flexion, neck rotation, hand above shoulder level, and squatting or kneeling ranged between 0.42 and 0.55 . The correlation coefficients for the questionnaire items were higher in general, and the accuracy better, for those with no low-back pain than for those with pain. The duration of trunk flexion, neck flexion and hand above shoulder level was overestimated in the questionnaires and less so in the logbooks.

Conclusions Self-administered questionnaires may help to classify groups with heterogeneous occupational tasks according to some work-load factors. The accuracy of the assessments is not good for studying quantitative exposure-effect relationships, however. The logbook method might give more valid information. The perception of musculoskeletal pain may bias the self-assessment of work load.
\end{abstract}

Key terms diary, ergonomics, logbook, low-back pain, neck pain, physical exposures, questionnaire studies, work analysis.

Numerous epidemiologic studies have attempted to investigate the role of physical load factors in low-back, neck-shoulder and upper limb disorders $(1-3)$. Several risk factors have been recognized at a qualitative level. For effective preventive measures, detailed information on quantitative exposure-effect relationships is needed.

Both subjective and objective methods have been used to assess work load. The objective methods range from occupation or job title through walk-through classifications, job checklists and observations to direct measurements (4). A decrease in versatility and an increase in accuracy and cost occurs as one moves from the beginning to the end of this list of methods. Direct measurements are costly, and their laboriousness makes them less feasible for use in epidemiologic studies, especially if information is needed concerning long-term work exposure.

It has been recently emphasized that even in seemingly monotonous tasks exposure to some commonly recorded physical load factors varies largely between individuals (5). Such observations emphasize the need for exposure data on an individual basis, especially when populations are studied that have not been primarily selected according to their expected exposure to physical load.

Subjective assessment of exposure to various physical work-load factors by questionnaires or logbooks offers a quick and less costly method with which to collect information on an individual basis. The duration or frequency of various intensity levels of physical load fac-

\section{Finnish Institute of Occupational Health, Helsinki, Finland.}

Reprint requests to: Dr Eira Viikari-Juntura, Department of Physiology, Finnish Institute of Occupational Health, Topeliuksenkatu 41 a A, FIN-00250 Helsinki, Finland. 
tors has usually been assessed as absolute values (6) or proportions of time for a given time period (7). The crucial question is how valid data can be obtained from this source of information. Previous studies suggest that the presence of some physical load factors, such as the manual handling of heavy objects and some extreme work postures, can be recognized by self-administered questionnaires. Additional grading of the physical work

\section{Study populations}

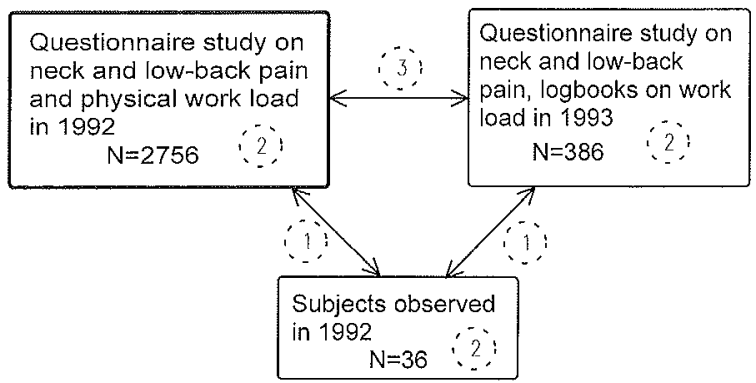

Figure 1. Study groups for the different objectives of the study. Numbers from 1 to 3 within the circles denote the different study objectives.

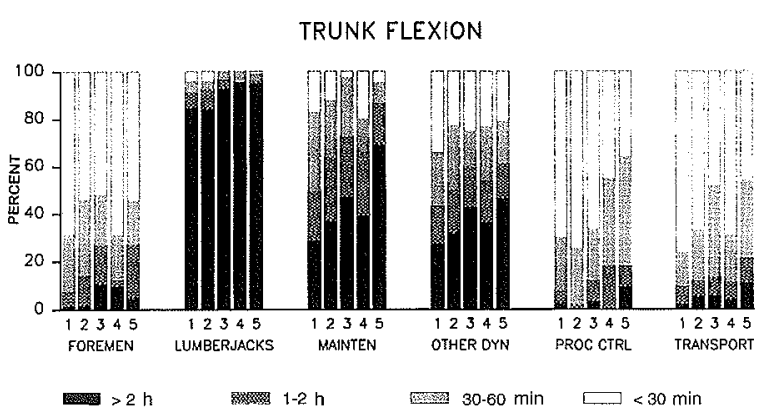

SITTING

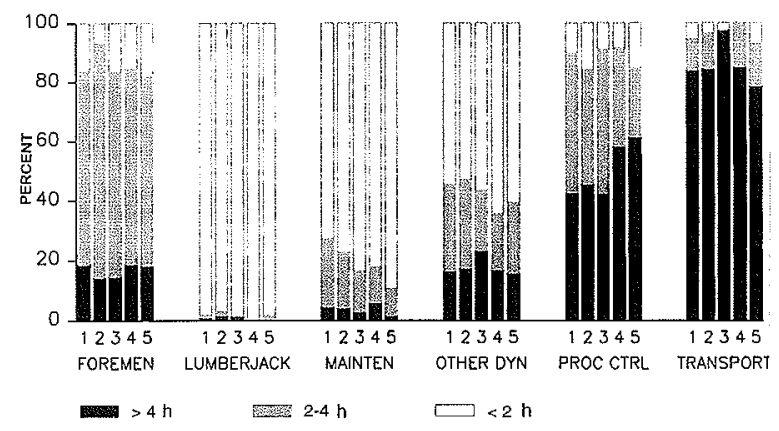

Figure 2. Questionnaire-based exposure assessment of trunk flexion and sitting by occupation and low-back and neck pain group $(\mathrm{N}=2756$ ). [Pain group: 1 = no neck and no low-back pain, 2 = intermediate level of neck or low-back pain, 3 = severe neck pain, $4=$ severe low-back pain, 5 = severe neck and low-back pain; occupation: foremen = foremen in forestry $(\mathrm{N}=339)$, lumberjacks $(\mathrm{N}=708)$, mainten = maintenance men $(N=684)$, other dyn = workers in other dynamic tasks $(N=623)$, proc $\mathrm{ctrl}=$ process control workers $(\mathrm{N}=190)$, transport $=$ transportation workers $(\mathbb{N}=212)]$ loads has generally not been possible (7). In cross-sectional studies the perception of symptoms can bias the self-assessment of work load (7).

The objectives of this study were (i) to estimate the validity of self-assessed physical work load by questionnaire and logbook against task analysis and observation, (ii) to investigate the factors (job type and low-back or neck pain) that affect the self-assessment of physical work load, and (iii) to compare work load assessments between the questionnaire and logbook.

\section{Subjects and methods}

\section{General design}

The subjects of this study were selected from a group of male workers participating in an investigation on musculoskeletal disorders (MUSKELI project) in a large company in the Finnish forest industry. Responses to a questionnaire on work load, general health, and musculoskeletal pain were received in March 1992 from 2756 workers. The response rate was $75.3 \%$. In September 1992 a group of 36 men was selected from the respondents, and their work tasks were analyzed and observed. Along with a follow-up questionnaire on symptoms, logbooks on physical work load were mailed in March 1993 to a subgroup ( $\mathrm{N}=1867)$ of those who had responded to the base-line questionnaire. The logbooks were returned by $35 \%$ of the men. Workers $(\mathrm{N}=386)$ who returned logbooks with good quality (for the definition of good quality, see the section Data Collection Instruments) and reported no change in work tasks between 1992 and 1993 were selected for the analysis. Figure 1 shows the different populations of this study. The numbers from 1 to 3 have been inserted into the figure to indicate the specific objective for which the different populations were used.

\section{Study populations}

Workers who replied to the 1992 questionnaire. The workers $(\mathrm{N}=2756)$ who returned the questionnaire in 1992 represented six occupational groups. (See the legend of figure 2.) The classification was performed by the authors based on job title and code, using information from workplace visits, discussions with several foremen, and the occupational physiotherapist of the company, independent of the questionnaire data on physical work load. The mean age of this population was 42.8 (SD 9.5) years. Ninety-seven percent had had their current work tasks at least two years, and $87 \%$ had done their current jobs at least five years.

Workers who returned logbooks in 1993. Three logbooks were mailed to 1867 men. The logbooks were returned 
by 649 men (35\%), and 569 of these men ( $88 \%$ ) returned three logbooks with good quality. Foremen in forestry had the highest response rate $(52 \%)$. The proportion of workers returning three logbooks with good quality was slightly lower among the lumberjacks (76\%) than among the other occupational groups. Those who returned logbooks did not differ from the nonrespondents as regards age and prevalence of neck or low-back pain. We excluded 29 process control workers and 37 transportation workers from further analysis because the groups were too small to be broken down into subgroups according to low-back pain.

Because there was a time lag between the questionnaire study in 1992 and the filling out of the logbooks in 1993 and we compared some of the logbook items with the questionnaire data, we restricted the study group to those who reported no changes in their work between 1992 and 1993. The study group consisted of 386 men with a mean age of 43.5 (SD 8.2) years. In 1992, 98\% had had their current work tasks at least two years, and $87 \%$ had done their current jobs at least five years.

Observed workers. Altogether 36 men, 18 in tasks that were known to include awkward or constrained body postures or lifting and 18 in tasks without such loading were selected. Both subgroups were comprised of nine men who had reported severe low-back pain (more than $30 \mathrm{~d}$ with low-back pain during the preceding 12 months) at the time of responding. For each worker with severe pain a referent with no pain (less than $8 \mathrm{~d}$ with low-back pain during the preceding 12 months) representing the same occupation and with a similar set of tasks was selected. This design was used to ensure the existence of the work-load factors of interest and to make symptomatic and nonsymptomatic groups comparable as regards work load. The group with high low-back load consisted of maintenance men, repairmen, carpenters, and truck drivers. The group with low low-back load consisted of foremen and process control workers. The mean age of the workers was 44.2 (SD 7.9) years. All but one had had their current tasks more than two years, and 92\% had done their jobs more than five years.

The 1992 questionnaire was available for all 36 workers, and 28 of them had logbooks with good quality.

\section{Data collection instruments}

Questionnaire. The self-administered questionnaire included 150 items, 10 of which were on physical work load (appendix). The questions had three- to four-point ordinal scales. The different body postures were clarified with manikins.

Logbook. Most items of the logbook were selected to correspond with those of the questionnaire. The ques- tionnaire item concerning repetitive movements of the wrist or fingers was replaced by an item concerning strenuous manual activities, and walking was measured as duration instead of distance. Neck rotation was not included. The logbook consisted of the following items: frequency of lifting, carrying or transferring loads weighing 6-15, 16-25, and $>25 \mathrm{~kg}$ manually; duration (in minutes per each workhour) of sitting, walking, standing, kneeling or squatting, and driving a motor vehicle; duration of work with trunk bent forward, neck bent forward, and hand above shoulder level; and duration of work involving strenuous manual activities. Similar manikins to those in the questionnaire were used to illustrate trunk flexion, neck flexion, and hand above shoulder level. The subjects were instructed to record the logbook items after each workhour on three typical workdays when they were performing their own work tasks. The logbooks could be folded to fit in a pocket, and a pen was mailed with them. The phone numbers of the researchers were included in the information sheet so that the workers could ask for additional information when needed.

The logbooks were classified according to quality, and only those with good quality were included in the analyses. The prerequisite for good quality was that all items be filled out and the sum of sitting, walking, standing, kneeling or squatting, and driving a motor vehicle was $60 \pm 10 \mathrm{~min}$ per each hour.

\section{Task analysis, observation and pedometer measurement.} The task analyses, observations, and pedometer measurements were performed in September-December 1992. Before the observations an occupational physiotherapist and an ergonomist interviewed the workers to make a complete list of their daily tasks and their durations. They checked also that no changes in the tasks had occurred between the filling out of the questionnaire and the interview.

The goal was to observe the worker performing each task belonging to his duties. Exposure to each physical load factor was then calculated on the basis of the task analysis and observation. The durations or frequencies that the worker was observed in each physical load category were multiplied by the number of repetitions of the task in question during one workday. Finally, the durations or frequencies of the physical load factors from different tasks were added. Complete coverage of the tasks is easily attained for a short-cycle job, but such coverage becomes more difficult as the variability of the tasks increases. For our study groups it was possible to catch $50 \%$ to $90 \%$ (median $75 \%$ ) of the workday for observation in the high low-back load group and $30 \%$ to 95\% (median 83\%) in the low low-back load group. In the latter group there were some tasks with long duration during which the occurrence of most of the physical load 
factors that were observed was unlikely, for example, sitting at a meeting. These tasks were therefore not observed. The total time of observation of one worker ranged from 2 to 90 (median 18) $\mathrm{min}$, and the observation extended typically over several days.

The observations were performed by the occupational physiotherapist using the portable ergonomic observation (PEO) method (8), which is a computerized method utilizing a notebook personal computer. Observations are recorded directly at the workplace and include postures of the hand, neck and trunk, repetitive motions of the hands, lifting and other manual handling of objects with different weights, and kneeling or squatting. For the different body postures, recordings are made when the posture is started and terminated, making it possible to obtain both the frequency and duration of the posture. For the lifts only the start was registered, and the method therefore gave only the frequency of these events. The criterion was 20 degrees for trunk and neck flexion and 45 degrees for trunk and neck rotation.

Sitting hours were estimated by the occupational physiotherapist on the basis of the task analysis and the observations. Walked distance was measured with a pedometer (Fitty 3 electronic, Kaspar \& Richter, Germany) (9).

\section{Statistical methods}

Spearman rank correlation coefficients were computed between the self-assessments (questionnaire or logbook) and observations of different physical load factors. To compare the durations of the work-load factors between the questionnaire and observation methods, the observed time was classified according to the categories in the questionnaire (appendix).

The effect of low-back pain on the self-assessment (questionnaire and logbook) of physical work-load factors was investigated by logistic regression. For this analysis, the questionnaire responses were dichotomized. In order to make this analysis concerning the logbook comparable with that of the questionnaire, the logbook as- sessments were also categorized according to a classification similar to that used for the questionnaire.

To analyze the contribution of different sources of variance in the work-load assessments in the logbook, variance components were computed for the different physical work-load factors. The sources of total variance were the variance between occupational groups, between workers within groups, and between workdays for individual workers. The "Proc nested" procedure in SAS software was used (10). Some work-load factors were rarely reported by some occupational groups. We excluded those occupational groups from the analysis in which the work-load factor in question was not reported by more than $30 \%$ of the subjects. Therefore, all the manual handling items were excluded from the analysis.

\section{Results}

\section{Validity of self-assessed work load}

Questionnaire versus observation and pedometer measurements. The Spearman rank correlation coefficients for the frequency of manual handling, duration of trunk flexion, neck rotation, hand above shoulder level, and squatting or kneeling ranged between 0.42 and 0.55 . Trunk rotations exceeding 45 degrees and manual handling of objects weighing more than $15 \mathrm{~kg}$ occurred rarely during the observations, and these items could not therefore be validated. The correlation between self-assessed and observed time with the neck in flexion and work involving repetitive wrist or finger movements was poor (table 1). The workers overestimated the time spent with the trunk in flexion and the arm above shoulder level.

The self-assessed sitting hours correlated well with the physiotherapist's estimation. The assessment of walked distance showed a fairly good correlation coefficient with the pedometer measurement. Most of the selfassessments were, however, in the category of $1-5 \mathrm{~km}$,

Table 1. Medians of the questionnaire and observation ratings of the work-load factors for the workers with high or low low-back load.

\begin{tabular}{|c|c|c|c|c|c|}
\hline \multirow[t]{2}{*}{ Work-load factor } & \multicolumn{2}{|c|}{$\begin{array}{l}\text { Workers with high load } \\
\qquad(N=18)\end{array}$} & \multicolumn{2}{|c|}{$\begin{array}{l}\text { Workers with low load } \\
\qquad(N=18)\end{array}$} & \multirow[t]{2}{*}{ Correlationa } \\
\hline & Questionnaire & Observed & Questionnaire & Observed & \\
\hline Lifting, carrying, transferring 6-15 kg (frequency) & 8 & 18.1 & 0 & 0 & $0.49^{* *}$ \\
\hline Trunk flexion (duration in hours) & $1-2$ & 0.7 & $<1 / 2$ & 0.1 & $0.42^{* *}$ \\
\hline Neck flexion (duration in hours) & $2-4$ & 0.9 & $2-4$ & 1.0 & $0.15^{\mathrm{b}}$ \\
\hline Neck rotation (duration in hours) & $<1 / 2$ & 0.0 & $1 / 2-1$ & 0.0 & $0.55^{\star \star \star}$ \\
\hline Hand above shoulder level (duration in hours) & $1 / 2-1$ & 0.1 & $<1 / 2$ & 0.0 & $0.55 * * *$ \\
\hline Repetitive wrist or finger movements (duration in hours) & $2-4$ & 0.2 & $2-4$ & 0.1 & $0.26^{b}$ \\
\hline Sitting (duration in hours) & $<2$ & 1.0 & $>4$ & 5.0 & $0.86^{* * *}$ \\
\hline Squatting or kneeling (duration in hours) & $<1 / 2$ & 0.0 & $<1 / 2$ & 0.0 & $0.42^{\star *}$ \\
\hline Walked distance $(\mathrm{km})$ & $1-5$ & 6.3 & $1-5$ & 3.4 & $0.65^{* * *}$ \\
\hline
\end{tabular}

a Spearman rank correlation coefficient between the questionnaire and observation ratings, high-load and low-load groups combined.

- Not significant.

${ }^{*} P<0.05,{ }^{* *} P<0.01,{ }^{* * *} P<0.001$ (one-sided). 
because those walking more than $5 \mathrm{~km}$ per day underestimated the distance walked.

Among the workers with high low-back load, the correlation coefficient was higher for hand above shoulder level (0.65) and lower (0.11) for squatting or kneeling than among the total study population.

With two exceptions, the self-assessed and observed values showed better correlations for the workers with no pain than for the workers with severe low-back pain (table 2). The workers with severe pain overestimated the duration of trunk flexion, hand above shoulder level, and sitting, whereas the workers with no pain did not.

Logbook versus observation. The correlation coefficients were generally a little higher between the logbook and the observations than between the questionnaire and observations (table 3 ). The durations based on the logbooks and observations were fairly close to each other. For the workers with high low-back load, the correlation coefficient was higher for manual handling (0.76) and neck flexion (0.59) and lower for kneeling or squatting (0.30) than for the total study population.

\section{Effect of job type and low-back or neck pain on self- assessed work load}

Questionnaire assessment. The occupational groups differed clearly from each other regarding the self-assessed exposure to all physical work-load factors (trunk flexion and sitting shown as examples in figure 2). There was also a uniform pattern of longer duration of exposure for the workers with severe neck or low-back pain than for those with less or no pain. This pattern could not be seen for sitting.

The effect of low-back pain on the assessment of the physical load factors was investigated by logistic regression by adjusting for the effect of occupational group. The pain status of the worker was entered in the model as a three-level factor, namely, no low-back or neck pain, intermediate level of low-back or neck pain, and severe low-back pain during the preceding 12 months. Having severe low-back pain increased the risk of reporting high durations or frequencies of physical load. The duration of sitting was the only exception. The odds ratios (OR) for the other work-load factors ranged from 1.6 to 2.6 , and the $95 \%$ confidence intervals $(95 \% \mathrm{CI})$ were, in all cases, above 1 . The highest $\mathrm{OR}$ values were those for trunk flexion (OR of severe low-back pain 2.6, 95\% CI $1.9-3.4$ ) and neck rotation (OR of severe low-back pain $2.5,95 \%$ CI $1.9-3.2$ ). The lowest OR values were those for hand above shoulder level (OR of severe low-back pain $1.6,95 \% \mathrm{Cl} 1.2-2.1$ ), kneeling or squatting (OR of severe low-back pain 1.6, 95\% CI 1.2-1.9), and distance walked (OR of severe low-back pain $1.6,95 \% \mathrm{CI}$ 1.3 - 2.2). No interactions were detected between occupation and low-back pain.

Table 2. Medians of the questionnaire and observation ratings of the work-load factors for the workers with severe or no low-back pain.

\begin{tabular}{|c|c|c|c|c|c|c|}
\hline \multirow[t]{2}{*}{ Work-load factor } & \multicolumn{3}{|c|}{$\begin{array}{l}\text { Workers with severe low-back pain } \\
\qquad(N=18)\end{array}$} & \multicolumn{3}{|c|}{$\begin{array}{l}\text { Workers with no low-back pain } \\
\qquad(N=18)\end{array}$} \\
\hline & Questionnaire & Observed & Correlation ${ }^{\mathrm{a}}$ & Questionnaire & Observed & Correlation ${ }^{\mathrm{a}}$ \\
\hline Lifting, carrying, transferring 6-15 kg (frequency) & 2.5 & 0 & $0.34^{b}$ & 1 & 0 & $0.55^{*}$ \\
\hline Trunk flexion (duration in hours) & $1 / 2-1$ & 0.1 & $0.62^{\star *}$ & $<1 / 2$ & 0.3 & $0.30^{b}$ \\
\hline Neck flexion (duration in hours) & $2-4$ & 1.1 & $-0.22^{b}$ & $<2$ & 0.8 & $0.47^{*}$ \\
\hline Neck rotation (duration in hours) & $1 / 2-1$ & 0.0 & 0.58 ** & $1 / 2-1$ & 0.0 & $0.51^{*}$ \\
\hline Hand above shoulder level (duration in hours) & $1 / 2-1$ & 0.0 & $0.51^{*}$ & $<1 / 2$ & 0.0 & $0.71^{* *}$ \\
\hline Repetitive wrist or finger movements (duration in hours) & $2-4$ & 0.2 & $0.18^{b}$ & $2-4$ & 0.0 & $0.37^{\circ}$ \\
\hline Sitting (duration in hours) & $>4$ & 3.5 & $0.85^{* * *}$ & $2-4$ & 3.0 & $0.87^{* \star *}$ \\
\hline Squatting or kneeling (duration in hours) & $<1 / 2$ & 0.0 & $0.34^{b}$ & $<1 / 2$ & 0.0 & $0.50^{*}$ \\
\hline Walked distance $(\mathrm{km})$ & $1-5$ & 4.6 & $0.53^{*}$ & $1-5$ & 4.0 & $0.77^{* *}$ \\
\hline
\end{tabular}

a Spearman rank correlation coefficient between the questionnaire and observation ratings.

b Not significant.

${ }^{*} P<0.05,{ }^{* *} P<0.01$, *** $P<0.001$ (one sided).

Table 3. Medians of the logbook and observation ratings of the work-load factors for the workers with high or low low-back load.

\begin{tabular}{|c|c|c|c|c|c|}
\hline \multirow[t]{2}{*}{ Work-load factor } & \multicolumn{2}{|c|}{$\begin{array}{l}\text { Workers with high load } \\
\qquad(N=12)\end{array}$} & \multicolumn{2}{|c|}{$\begin{array}{l}\text { Workers with low load } \\
\qquad(N=16)\end{array}$} & \multirow[t]{2}{*}{ Correlation ${ }^{2}$} \\
\hline & Logbook & Observed & Logbook & Observed & \\
\hline Lifting, carrying, transferring 6-15 kg (frequency) & 7.5 & 5.1 & 0.0 & 0.0 & $0.51^{* *}$ \\
\hline Trunk flexion (duration in hours) & 1.1 & 0.7 & 0.0 & 0.1 & $0.55^{* *}$ \\
\hline Neck flexion (duration in hours) & 1.1 & 0.8 & 2.1 & 1.3 & $0.52^{* *}$ \\
\hline Hand above shoulder level (duration in hours) & 0.2 & 0.1 & 0.0 & 0.0 & $0.45^{\star}$ \\
\hline Sitting (duration in hours) & 1.2 & 1.5 & 5.4 & 5.0 & $0.72^{* * *}$ \\
\hline Kneeling or squatting (duration in hours) & 0.9 & 0.0 & 0.0 & 0.0 & $0.51^{\text {* * }}$ \\
\hline
\end{tabular}

a Spearman rank correlation coefficient between the logbook and observation ratings, high load and low load groups combined.

${ }^{*} \mathrm{P}<0.05,{ }^{* *} \mathrm{P}<0.01,{ }^{* * *} \mathrm{P}<0.001$ (one sided). 
Logbook assessment. The day-to-day variance for the individual workers ranged between $9 \%$ and $24 \%$ of the total variance (table 4 ). The between-worker variance was large, constituting almost or more than half of the total variance. The between-group variance was close to or lower than $25 \%$ for most of the work-load factors. The between-group variance was large for strenuous manual activity when only lumberjacks and maintenance men were included in the analysis.

Clear differences could be seen between the occupational groups in the assessments of most of the workload factors. There was no pattern of association between the work-load assessments and low-back pain. With the use of logistic regression modeling of the physical load factors and adjustment for occupational group, the OR values for the effect of low-back pain ranged from 0.7 to 1.4 , the $95 \%$ confidence intervals including one in all instances. In the model for trunk flexion, the OR for severe low-back pain was 1.2 (95\% CI $0.6-2.4)$.

\section{Comparison of questionnaire and logbook items}

Long durations of neck flexion ( $>4 \mathrm{~h}$ ) and hand above shoulder level $(>2 \mathrm{~h}$ ) were more frequently reported in the questionnaire than in the logbooks (figure 3 ). Long durations of trunk flexion $(>2 \mathrm{~h}$ ) were estimated more frequently in the questionnaire by the lumberjacks and the maintenance men but not by the other occupational groups. Kneeling and squatting exceeding $1 \mathrm{~h}$ per day was more frequently reported in the logbooks than in the questionnaire.

Table 4. Contribution of different sources to the total variance for different logbook items.

\begin{tabular}{|c|c|c|c|c|}
\hline \multirow[t]{2}{*}{ Work-load factor } & \multirow{2}{*}{$\begin{array}{l}\text { Total variance } \\
\text { component }\end{array}$} & \multicolumn{3}{|c|}{ Contribution to total variance $(\%)$} \\
\hline & & $\begin{array}{l}\text { Between } \\
\text { occupational } \\
\text { groups }\end{array}$ & $\begin{array}{l}\text { Between } \\
\text { workers within } \\
\text { groups }\end{array}$ & $\begin{array}{c}\text { Between work } \\
\text { days for individual } \\
\text { workers }\end{array}$ \\
\hline Trunk flexion ${ }^{a}$ & 11852 & 23 & 58 & 19 \\
\hline Neck flexiona & 10923 & 3 & 77 & 20 \\
\hline Sitting $^{a}$ & 9723 & 24 & 62 & 14 \\
\hline Standinga & 8976 & 27 & 49 & 24 \\
\hline Walkinga $^{\mathrm{a}}$ & 8161 & 25 & 54 & 21 \\
\hline Strenuous manual activity ${ }^{b}$ & 25010 & 49 & 42 & 9 \\
\hline Squatting or kneeling ${ }^{b}$ & 8314 & 15 & 61 & 24 \\
\hline
\end{tabular}

a Lumberjacks, maintenance men, and workers in other dynamic tasks included ( $N=351-353$ ).

- Lumberjacks and maintenance men included $(N=192-194)$.

TRUNK FLEXION

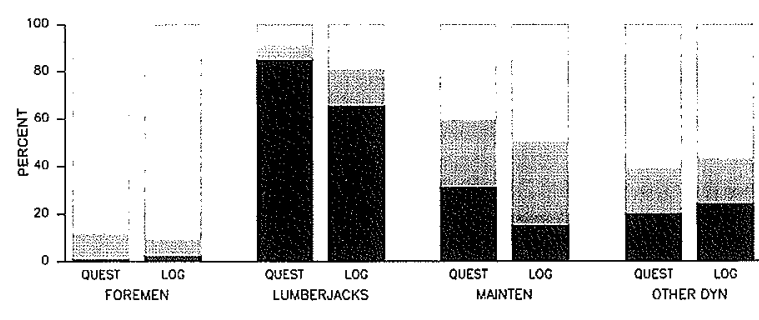

$1.2 \mathrm{~h}$

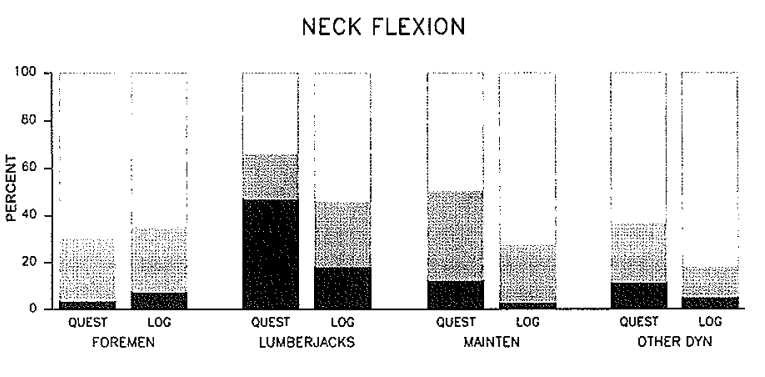

$>4 \mathrm{~h}$

$\square<2 \mathrm{~h}$
KNEELING OR SQUATTING

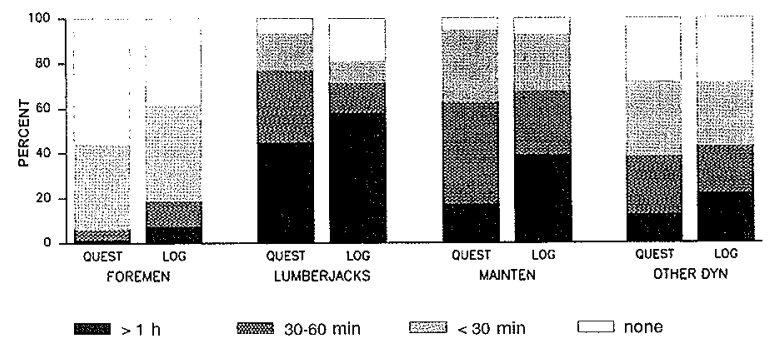

Figure 3. Comparison of assessment of selected work-load factors by questionnaire and logbooks. Proportions (\%) of workers in different workload categories. [Occupation: foremen $=$ foremen in forestry $(N=80)$, lumberjacks $(N=88)$, mainten = maintenance men $(N=104)$, other dyn $=$ workers in other dynamic tasks $(\mathrm{N}=114)]$ 


\section{Discussion}

\section{Validity of self-assessment}

Self-assessments of the physical work-load factors by the use of the questionnaire and logbooks showed fairly good rank correlation coefficients with observations made by a trained physiotherapist. The validity was somewhat better for the logbooks than for the questionnaire method.

In the group of 36 subjects for whom task analyses and observations served as the validity criterion, the correlation coefficients of the questionnaire items were higher in general, and the accuracy of the estimations was better for those with no low-back pain than for those with severe pain. Furthermore, among the larger group who returned the questionnaire, great differences were seen within the occupational groups in the assessments of the work-load factors between those with severe lowback or neck pain and those with no pain. This phenomenon was the most notable for the items on trunk flexion and neck rotation. Because no standard was available for this larger group, we do not know about the true levels of the work load of the symptomatic and nonsymptomatic workers. It is therefore possible that the levels of work load could also, in reality, have been different among the symptomatic and the nonsymptomatic workers. The results concerning both the smaller and larger groups suggest, however, that there was a differential bias due to severe low-back and neck pain for most of the work-load factors. This bias may lead to spurious associations between musculoskeletal pain and self-reported physical work load in cross-sectional studies. A differential bias due to low-back pain was not found for the logbook items.

The durations of certain postures, such as trunk flexion, neck flexion, and hand above shoulder level, were clearly overestimated in the questionnaires. The implication is that if results from epidemiologic studies with similar questions on physical load are used as the basis for recommendable levels of work loads, such levels are likely to be too high. The overestimation was smaller with the logbooks, and therefore an estimation on an hour-to-hour basis seems to lead to smaller error than the duration average over the workday.

Comparisons of our results with those from other studies have some limitations. Most other investigators have studied the validity of exposure assessment concerning a defined workday $(6,11)$ or a short period of the workday (7) and not averaged exposures for typical workdays. In such studies the observations have been performed simultaneously so that the workers have been aware of the observation procedure. This practice may force the workers to estimate their physical loads in more detail than what they would do in a large-scale epidemio- logic study with no observations or measurements. In some studies workers have assessed the proportions of defined time periods spent in various postures (7) and not the absolute durations. Only few studies have been undertaken to investigate the validity of the logbook method (6).

Our results agree with the results of Wiktorin et al (7) in that the duration of sitting showed the highest validity and the assessments of the durations of different postures of various body parts are inaccurate by the questionnaire method. To assess possible bias in the risk estimates due to the presence of musculoskeletal symptoms, Wiktorin et al compared the prevalence odds ratios for low-back or neck-shoulder complaints according to the questionnaire reports with those based on observational data. They found higher odds ratios for lifting and carrying, pushing, and pulling activities as assessed by the questionnaire than when assessed by observation. No statistically significant differences in the odds ratios were found for neck or trunk flexion nor for kneeling or squatting. We investigated the effect of low-back pain in the large population on the basis of the questionnaire data without any comparison with observation, but controlling for occupational group. Our results suggest more pronounced effects of low-back pain on a larger group of physical load factors than the results of Wiktorin et al do. This difference may be due to the fact that the criterion for "symptomatic" was stricter in our study (pain on more than $30 \mathrm{~d}$ during the preceding 12 months) than in their study (pain during the preceding 12 months), and therefore the contrast between symptomatic and nonsymptomatic subjects was sharper.

Burdorf (5) studied the proportion of worktime with trunk flexion and rotation by the OWAS (Ovako working posture analyzing system) observation method among five occupational groups. The between-group variance was $47 \%$ and $72 \%$ and variance between workers within groups was $24 \%$ and $12 \%$ for trunk flexion and rotation, respectively. The smaller variance between occupational groups and the larger variance between workers for most of the physical work-load factors in our study may have been due to inaccuracies in the self-assessments and to greater heterogeneity of the occupational groups.

\section{Problems with the validity criterion}

The "absolute truth" of the calculated durations and frequencies of the physical load factors based on observations may have been distorted by the following three types of error: (i) task analysis and sampling (not all tasks were observed; the proportion of the task of the workday may not have been correctly estimated), (ii) intraindividual variation in task performance, (iii) observation errors.

We suspect that the low correlation of self-assessed duration of kneeling or squatting, especially for the high 
low-back load group, was due to the fact that not all of the tasks involving squatting or kneeling were observed, rather than the workers' reporting of nonexistent kneeling or squatting. We tried to minimize such errors by attempting a full coverage of the daily tasks. Moreover, the frequency distribution of the tasks may, however, have been different at the time of observation from that at the time of responding to the questionnaire, despite the fact that the workers reported no change in their tasks.

To reduce error due to intraindividual variation, several observations would be needed per task (12). This was not done due to limited resources. The dichotomy and broadness of the subcategories of the PEO method tended to decrease the intraindividual variation.

The studies on the validity of the PEO method suggest that the registration of the duration of the different work-load factors, for example, trunk flexion and repetitive finger and wrist movements, are fairly valid, whereas the observation of neck flexion seems to be more difficult (8). In the most dynamic tasks the validity was probably lower due to the large number of factors observed simultaneously.

\section{Questionnaire and logbook as data collection instruments}

The response rate was high for our questionnaire and the quality of returned questionnaires was good. There were few missing data in the questions on work load $(0.5-$ $1.6 \%$ of the respondents, depending on the item). An exception to this rule was the three-item question on the frequency of manual handling activities and the question on sitting, $5.1-5.2 \%$ of the subjects having left the items unanswered. The nonresponse rate to the question on manual handling activities was high (12.7\%) especially for the lumberjacks. It is understandable that those who carry chain saws for long durations have difficulty in estimating this activity as frequency per day.

The very low response rate to the logbooks suggests that, at least in the form used in our study, the logbook is not a useful instrument for data collection in large epidemiologic surveys. Due to the higher validity of its information, it should, however, be considered a potential instrument in situations in which the investigators are themselves in the field and can motivate the study participants. Because logbooks with good quality were returned by only about a third of the subjects, the results are not representative of the different occupational groups. Day-to-day variance contributing little to the total variance in the logbook assessments suggests that keeping one or two logbooks may be sufficient in jobs similar to those in our study.

\section{Concluding remarks}

Self-administered questionnaires may help to classify groups with heterogeneous occupational tasks according to some physical work-load factors known to be risk factors of musculoskeletal disorders. The accuracy of the assessments of most work-load factors by self-administered questionnaires is not good for studying quantitative exposure-effect relationships. Our results suggest that information collected on some physical load factors by the logbook method might be valid enough for studying exposure-effect relationships. The difficulty and laboriousness of keeping the logbook is a drawback restricting its use in epidemiologic studies. The perception of musculoskeletal pain may bias the self-assessment of work load.

\section{Acknowledgments}

We thank Mr Mauno Ahonen for carrying out the task analyses in the field.

We are grateful to the Finnish Work Environment Fund for its financial support of this study.

\section{References}

1. Burdorf A. Exposure assessment of risk factors for disorders of the back in occupational epidemiology. Scand J Work Environ Health 1992;18:1-9.

2. Hagberg M, Wegman DH. Prevalence rates and odds ratios of shoulder-neck diseases in different occupational groups. $\mathrm{Br} \mathrm{J}$ Ind Med 1987;44:602-10.

3. Stock S. Workplace ergonomic factors and the development of musculoskeletal disorders of the neck and upper limbs: a meta-analysis. Am J Ind Med 1991;19:87-107.

4. Wilson JR, Corlett EN. Evaluation of human work: a practical ergonomics methodology. London, Washington (DC): Taylor \& Francis, 1990.

5. Burdorf A. Sources of variance in exposure to postural load on the back in occupational groups. Scand J Work Environ Health 1992;18:361-7.

6. Burdorf A, Laan J. Comparison of methods for the assessment of postural load on the back. Scand J Work Environ Health 1991;17:425-9.

7. Wiktorin C, Karlqvist L, Winkel J, Stockholm MUSIC I study group. Validity of self-reported exposures to work postures and manual materials handling. Scand J Work Environ Health 1993;19:208-14.

8. Fransson-Hall C, Gloria R, Karlqvist L, Wiktorin C, Winkel J, Kilbom $\AA$, et al. A portable ergonomic observation method (PEO) for computerized on-line recording of postures and manual handling. Appl Ergon 1995;26:93-100.

9. Selin K, Winkel J, Stockholm MUSIC I Study Group. Evaluation of two instruments for recording sitting and standing postures and number of footsteps. Appl Ergon 1994;25:41-6.

10. SAS Institute Inc. SAS/STAT user's guide, version 6 , 4th ed, vol 2. Cary (NC): SAS Institute Inc, 1989.

11. Baty D, Buckle PW, Stubbs DA. Posture recording by direct observation, questionnaire assessment and instrumentation: a comparison based on a recent field study. In: Corlett N, Wilson J, Manenica I, editors. The ergonomics of working pos- 
tures: proceedings of the first international occupational ergonomics symposium; 1985 Aptil 15--17. London and Philadelphia: Taylor \& Francis 1986;283-91.
12. Burdorf A. Reducing random measurement error in assessing postural load on the back in epidemiologic surveys. Scand J Work Environ Health 1995;21:15-23.

\section{Appendix}

\section{Items validated in the self-administered questionnaire}

1. On the average, how many times per workday do you lift, carry or transfer manually loads of different weights listed below?

$$
\begin{aligned}
& 6-15 \mathrm{~kg} \_ \text {times } \\
& 16-25 \mathrm{~kg} \_ \text {times } \\
& \text { More than } 25 \mathrm{~kg} \_ \text {times }
\end{aligned}
$$

2. On the average, how many hours per workday do you work with your trunk bent forward (standing or kneeling)?
1 Less than $1 / 2$ hour
$21 / 2-1$ hour
$31-2$ hours
4 More than 2 hours

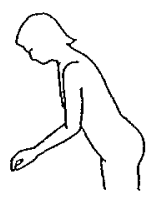

3. How frequently do you rotate your trunk during an ordinary workday?
1 Not at all
2 Rarely
3 Fairly often
4 Often

4. On the average, how many hours per workday do you work with your neck bent forward?
1 Less than 2 hours
$22-4$ hours
3 More than 4 hours

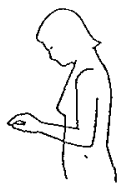

5. On the average, how many hours per workday do you work with rotated neck?
1 Less than $1 / 2$ hour
$21 / 2-1$ hour
3 More than 1 hour

Received for publication: 14 August 1995
6. On the average, how many hours per workday do you work with your hand above shoulder level? (Object of work in the shaded area of the figure.)

1 Less than $1 / 2$ hour

$21 / 2-1$ hour

$31-2$ hours

4 More than 2 hours

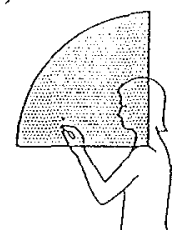

7. On the average, how many hours per workday do you perform tasks involving repetitive movements of the wrist or fingers (eg, keyboard work, driving screws)?
1 Not at all
2 Less than 2 hours
$32-4$ hours
4 More than 4 hours

8. On the average, how many hours per workday do you sit in your work?
1 Less than 2 hours
2 2-4 hours
3 More than 4 hours

9. On the average, how many hours per workday do you work kneeling or squatting?
1 Not at all
2 Less than $1 / 2$ hour
$31 / 2$ to 1 hour
4 More than 1 hour

10. On the average, how many kilometers do you think you walk during an ordinary workday?
1 Less than $1 \mathrm{~km}$
21 to $5 \mathrm{~km}$
3 More than $5 \mathrm{~km}$ 